\title{
CONFIGURAÇÃO DAS IMAGENS IDEATIVAS, PLANEJAMENTTO E REDUÇÃO DE RISCOS: A IMPLANTAÇÃO DO SISTEMA ERP EM UMA INSTITUIÇÃO PÚBLICA DE ENSINO
}

\author{
IMAGES CONSTRUCTIONS TECHNIC, \\ PLANNING AND RISK REDUCTION: THE \\ IMPLANTATION OF THE ERP'S SYSTEM IN \\ A PUBLIC EDUCATIONAL INSTITUTION
}

Recebido 28/08/2012 Aceito $28 / 11 / 2013$

\author{
Henrique Cordeiro Martins ${ }^{1}$ \\ Maria Dalva Martins ${ }^{2}$ \\ Cristiana Fernandes de Muylder ${ }^{3}$ \\ Carlos Alberto Gonçalves ${ }^{4}$ \\ Alexandre Teixeira Dias ${ }^{5}$
}

\section{RESUMO}

Este estudo descreve as ações programadas para a implantação do sistema ERP, identificando exigências, expectativas, benefícios, limitações e imagens ideativas construídas por seus futuros usuários. A pesquisa foi qualitativa e quantitativa, descritiva, no Instituto Federal Minas Gerais (IFMG), primeira instituição pública federal de ensino tecnológico a implantar o sistema ERP. Os dados foram coletados por meio de questionário de evocação livre e de entrevista semiestruturada. A aplicação da técnica de configuração de imagens permitiu identificar as imagens dos servidores sobre a ferramenta de ERP. As imagens positivas representam os fatores de sucesso enquanto as imagens negativas sugerem resistência à utilização do sistema. De forma geral, os resultados apontam que as ações planejadas para a implantação do sistema no IFMG, bem como as imagens construídas por seus usuários-chave, são favoráveis à construção da identidade da instituição e a sua unicidade. Espera-se contribuir com outros estudos relativos à implantação de sistemas de gestão empresarial em instituições públicas.

Palavras-chave: ERP; Planejamento; Técnica de configuração de imagens; Serviço público; Instituto federal de ensino

\footnotetext{
${ }^{1}$ Possui graduação em Administração de Empresas pelo Centro Universitário Newton Paiva Ferreira e em Ciências pelo Centro Universitário Izabela Hendrix, MBA Executivo em Finanças e Mercado de Capitais pelo Instituto Brasileiro de Mercado de Capitais - IBMEC e doutorado em Administração pela Universidade Federal de Minas Gerais - UFMG. Atualmente é professor titular do programa de doutorado e mestrado acadêmico da Universidade FUMEC. Belo Horizonte, Minas Gerais, Brasil. E-mail: henrique.martins@fumec.br.

${ }^{2}$ Mestre em Administração. Universidade FUMEC, Instituto Federal de Minas Gerais - IFMG. Belo Horizonte, Minas Gerais, Brasil. E-mail: dalva.martins@ifmg.edu.br.

${ }^{3}$ Possui graduação em Ciência da Computação e especialização em Sistemas de Informação e Planejamento estratégico pela Pontífica Universidade Católica de Minas Gerais - PUC-Minas, mestrado em Economia Rural e doutorado em Economia Aplicada pela Universidade Federal de Viçosa - UFV. Atualmente é professora e pesquisadora dos Programas Stricto Sensu de Administração e Administração de sistemas de informação e gestão do conhecimento da Universidade FUMEC. Belo Horizonte, Minas Gerais, Brasil. E-mail: cristiana.muylder@fumec.br.

${ }^{4}$ Possui graduação em Engenharia Civil e especialização em Curso de Análise de Processamento de Dados pela Universidade Federal de Minas Gerais - UFMG, mestrado em Informática pela Pontifícia Universidade Católica do Rio de Janeiro - PUC-Rio e doutorado em Administração pela Universidade de São Paulo - USP. Atualmente é professor Associado da Universidade Federal de Minas Gerais e da Universidade FUMEC. Belo Horizonte, Minas Gerais, Brasil. E-mail: carlos@face.ufmg.br.

${ }^{5}$ Possui graduação, mestrado e doutorado em Administração pela Universidade Federal de Minas Gerais - UFMG. Atualmente é professor celetista da Universidade FUMEC. Belo Horizonte, Minas Gerais, Brasil. E-mail: alexandre.tdias@fumec.br.
} 


\section{ABSTRACT}

This article describes the ERP planning and implementation process that includes identifying requirements, expectations, benefits, limitations and the ideational images built by the future users. The research was qualitative and quantitative descriptive based in the Instituto Federal Minas Gerais (IFMG) case: the first Brazilian public federal institution of technological education to install the ERP's system. The data was collected based on free and semi-structured interviews. The images configuration technic use allowed identifying the user's images for the ERP software. The positive images represented the success factors and the negative images were related to aversion system implementation. Generally, the results indicated that the IFMG' ERP plans of implementation were propitious to build a unique identity. This paper aims also to contribute with others studies related with ERP implementation in public organizations.

Keywords: ERP; Planning; Images configuration technic; Public service: Federal educational institute.

\section{INTRODUÇÃO}

A crise econômica mundial e o fenômeno da globalização pressionam o Estado para mudanças e inovações, exigindo novos modelos de gestão cujo desafio está em romper com conceitos tradicionais e agregar valores e princípios da administração privada (ERKENS, 2010). Na visão de Erkens (2010), esses fenômenos foram decisivos para o processo de reforma da administração pública brasileira, tendo como marco a Emenda Constitucional 19, de 1998, que introduz o princípio da eficiência ao conjunto dos outros princípios da administração pública, ou seja, legalidade, impessoalidade, moralidade e publicidade, e que exige da administração pública o alcance de melhores resultados com os meios escassos de que dispõe e a menor custo.

No entendimento de Vilhena (2006), são algumas das exigências da Nova Gestão Pública: um planejamento orientador das políticas de gestão, uma política eletrônica de governo, a integração de redes e a democratização da informação, de forma a ofertar mais e melhores serviços à população. $O$ controle administrativo funciona previamente para evitar a corrupção, sendo necessário e rígido em todos os processos e no atendimento às necessidades da população (OLIVEIRA, 2007). A tentativa de controlar tudo na administração pública e de ditar o modo como as coisas deveriam ser feitas, regulando os procedimentos e controlando os insumos, fez com que se ignorassem resultados (TAMEZ, 2004).

O uso de novas tecnologias tem como ponto central os processos de informatização e, por ganhar cada vez mais espaço no dia a dia das organizações, provoca o advento da Tecnologia de Informação (TI), gerando um processo de profundas mudanças na cultura organizacional. Gama e Martinello (2006) consideram a TI como um processo que engloba todas as formas de tecnologia utilizadas para criar, armazenar, trocar e usar informação em suas várias formas (dados, voz, imagens estáticas e em movimento). Na visão de Tamae et al. (2005), o acesso à informação de forma inteligente tornou-se o ponto-chave para que as empresas públicas e privadas alcancem maior produtividade.

A integração dos vários sistemas de informação em um único provoca o que se denomina de sistema integrado de gestão, que retrata a combinação de processos, procedimentos e práticas adotados por uma organização para implementar suas políticas e atingir seus objetivos de forma mais eficiente que por meio de múltiplos sistemas. Esses sistemas compõem um fenômeno recente no panorama empresarial (WOOD JR; CALDAS, 1999), ganhando projeção na década de 1980.

Tal prática, de modo geral, ocasiona mudanças expressivas no ambiente organizacional, promovendo modificações de âmbito tecnológico e de processos (RODRIGUES, 2009). No início da década de 90, os sistemas integrados de gestão ganham espaço no mundo pro- 
dutivo com a implantação de ferramentas tecnológicas específicas, resultantes do crescimento dos negócios apoiados pela tecnologia da informação (TI) e incorporadas pelas empresas para auxiliar o gerenciamento dos negócios (OLIVEIRA, 2006), sendo uma delas o Enterprise Resource Planning (ERP) ou Planejamento de Recursos Empresariais. O sistema ERP despontou como uma tecnologia de vanguarda, sendo atualmente uma das mais utilizadas pelas empresas pró-ativas no cenário empresarial (OLIVEIRA, 2006). Trata-se de um sistema capaz de fornecer informações detalhadas sobre as operações da empresa, através de um software de planejamento que integra suas diferentes funções para criar operações mais eficientes (BUCKOUT, S.; FREY, E.; NEMEC JR, 1999).

Embora esteja em voga, a implantação de um sistema ERP tem sido considerada problemática em todo o mundo. Pesquisas revelam que os custos, a complexidade, as implicações e as políticas de um investimento nesse tipo de tecnologia são muito altos, não trazendo, aparentemente, os benefícios de competitividade e redução de custos prometidos (BUCKOUT; FREY; NEMEC JR, 1999); que muitas empresas calculam de forma errada os custos relativos a essa implantação; que incluem licenças do software, de hardware, de serviços de consultoria e de treinamento e, ainda, ajustes pós- implantação (MENDES; ESCRIVÃO FILHO, 2002); e que, em muitos casos, a implantação de projetos dessa categoria ultrapassa os orçamentos originalmente previstos.

O setor público, por estar inserido no moderno contexto econômicos das nações, tem sido motivado a implantar sistemas integrados de gestão com foco em ganhos de eficiência e eficácia em seus procedimentos (CATELLINO; BOTTER; ITELVINO, 2010). Esses aspectos, aliados às pretensões do paradigma gerencial, fortalecem a tendência da administração pública de importar práticas consideradas bem-sucedidas na iniciativa privada, na tentativa de trazer a lógica empresarial para o Estado.

Coerente com essa visão e com as exigências que ela impõe, o Instituto Federal Minas Gerais (IFMG), uma autarquia integrante da Rede Federal de Educação Profissional, Científica e Tecnológica, vinculada ao Ministério da Educação, encontra-se em processo de implantação do Sistema Integrado de Gestão, na modalidade ERP. Neste contexto, o que se pretende pesquisar é: visto que o sistema ERP é muito comentado no mundo empresarial; que sua implantação tem sido considerada problemática, lenta; que a relação custo/benefício não se equilibra; que ações do planejamento de sua implantação em uma instituição pública de ensino técnico poderiam minimizar as limitações relacionadas? Quais as imagens construídas pelos futuros usuários do sistema ERP em torno do conceito, relacionando-as com a receptividade ao projeto de implantação do sistema?

A partir dessas questões, o objetivo geral deste artigo é descrever as ações de planejamento relativas à implantação do Sistema Integrado de Gestão, na modalidade ERP, em uma instituição pública de ensino, capazes de minimizar os riscos inerentes à sua implantação e levantar as imagens ideativas construídas pelos futuros usuários do sistema, relacionando-as com a receptividade ao projeto de implantação.

Este estudo se justifica tendo em vista as exigências inerentes ao paradigma gerencial que fortalecem a tendência da administração pública de importar práticas bem sucedidas da iniciativa privada, reforçando a tentativa de trazer a lógica empresarial para o Estado. Além disso, uma conjugação de fatores justifica a implantação, pelo IFMG, do Sistema Integrado de Gestão, modalidade ERP, destacando-se: 1) a criação, em 2005, pelo Governo Federal, do Programa Nacional de Gestão Pública e Desburocratização, com o objetivo de promover uma gestão pública de excelência, tendo como uma de suas iniciativas a ampliação de ferramentas de gestão 
disponíveis; 2) a criação dos Institutos Federais de Educação, Ciência e Tecnologia, em 29 de dezembro de 2008, por força da Lei no 11.892 , provocando o surgimento de um novo desenho organizacional e, consequentemente, da necessidade de uma nova estratégia de administração (HADDAD, 2011).

\section{REFERENCIAL TEÓRICO}

\subsection{Sistema ERP: definição, constituição e objetivos}

Os sistemas integrados de gestão, também reconhecidos como sistemas de gestão empresarial, na modalidade ERP (Enterprise Resource Planning), são considerados como uma ferramenta de Tecnologia da Informação (TI) que apoia o gerenciamento de informações, voltado ao seu processamento de forma eficiente, transparente, íntegra e confiável (COSTA, 2009; SACCOL et al., 2003).

No início da década de 90, esses sistemas passaram a ser largamente utilizados pelas empresas (MENDES; ESCRIVÃO FILHO, 2002) devido a sua capacidade de fornecer informações precisas em tempo real e de forma integrada. Entre as explicações para esse fenômeno estão as pressões competitivas sofridas pelas organizações, que as obrigaram a rever seus processos e sua maneira de trabalhar, por reconhecerem a necessidade de coordenar melhor as suas atividades dentro de sua cadeia de valores, para eliminar desperdícios de recursos e reduzir o custo para melhor atenderem a um mercado global, altamente dinâmico e exigente (OLIVEIRA; RAMOS JUNIOR; ALBUQUERQUE, 2010; SOUZA; ZWICKER, 2000).

Buckout, Frey e Nemec Jr. (1999) apresentam o sistema ERP como um software de planejamento, mas sabe-se que ele não se limita a isso, e os próprios autores expandem essa definição ao mencionarem que ele integra as diferentes áreas da empresa, criando operações mais eficientes, permitindo a comunicação entre as áreas, fornecendo informações detalhadas e possibilitando, assim, o controle das funções por ele suportadas.

O sistema ERP compreende desde um conjunto de programas de computador até um sistema de informação gerencial que visa a apoiar as decisões estratégicas da empresa, resultando em um projeto de mudança organizacional, com reflexos na forma de operação da empresa, na estrutura e nos aspectos culturais. O princípio-chave do sistema ERP é a integração das diferentes funções da empresa para criar operações mais eficientes dos dados-chave e da comunicação entre as áreas da empresa, fornecendo informações detalhadas sobre suas operações (MENDES; ESCRIVÃO FILHO, 2002,) e dos departamentos [...] da organização no intuito de obter as informações de forma eficaz e oportuna (SOUZA; ZWICKER, 2003: 77).

Souza e Zwicker (2000) entendem que, nos sistemas ERP, os módulos resultam da reunião de funções correspondentes a uma mesma divisão departamental; o termo função, por sua vez, designa as diferentes operações realizadas em um sistema informatizado. No sistema ERP, a composição de todas as funções disponíveis forma o sistema transacional de informações que dá suporte aos processos de negócio.

Os sistemas ERP apresentam uma série de características que, tomadas em conjunto, os distinguem dos sistemas desenvolvidos internamente nas empresas e de outros tipos de pacotes comerciais. Essas características são importantes para a análise de possíveis benefícios e dificuldades relacionados com sua utilização e com os aspectos pertinentes ao sucesso de sua implementação (SOUZA; ZWICKER, 2000).

Por ser o sistema ERP um produto flexível, a organização pode adequar suas necessidades no projeto de implantação, no sentido que as particularidades sejam atendidas, os prazos 
cumpridos, auxiliando na definição do escopo das modificações, não perdendo foco no projeto, o que favorece o conhecimento das modificações introduzidas. Essa relação entre necessidades da organização e possibilidades do sistema é que provoca a criação de novos recursos de ERP (TAMAE et al., 2005), uma vez que esses sistemas tendem a acompanhar o ritmo das mudanças, sofrendo atualizações, trocas e ajustes constantes (SACCOL; SOUZA, 2010).

\subsection{Implantação do Sistema ERP}

Na implantação de um sistema ERP, "é determinante levantar os objetivos a serem alcançados, verificando os processos atuais e as possibilidades de mudança" (TAMAE et al., 2005, p.3). É importante considerar, como afirma Medeiros Jr, Perez e Shimizu (2010), que a expectativa em relação aos benefícios da utilização desse sistema é maior do que aquilo que as aplicações geralmente conseguem oferecer. A opção pela implantação de um sistema ERP sempre é uma decisão complexa (MEDEIROS JR; PEREZ; SHIMIZU, 2010), exigindo dos que têm poder decisório algumas habilidades, dentre as quais, destacam-se: - (...) avaliar a orientação estratégica da empresa, a sua visão de futuro, e identificar as necessidades de informação (MENDES; ESCRIVÃO FILHO, 2002:54); - (...) selecionar um fornecedor e um sistema adequado às demandas presentes e futuras da empresa, com foco na aderência às características específicas da organização, na flexibilidade da ferramenta para implementações e ajustes futuros, nos aspectos tecnológicos e na estrutura do fornecedor para suprimento de suporte técnico adequado, atualizações e atendimento a legislações específicas (CANUTO; CHEROBIM, 2010:72).

Uma primeira análise sobre o conteúdo dos ganhos e dificuldades relativos à implantação de sistemas integrados de gestão evidencia que os ganhos incidem sobre processos e que as dificuldades têm relação direta com o nível da prática gerencial. Entre os fatores que dificultam a implantação de um sistema ERP, destacam-se os relacionados aos custos inerentes ao projeto de implantação, reforçando o entendimento da existência de discrepância entre o que a empresa expressa em seus objetivos para a implantação do sistema e o que a execução evidencia.

Os sistemas ERP sempre requerem procedimentos de ajuste que podem ser representados pelas fases de adaptação, parametrização e customização, e, ainda pela localização e atualização (SOUZA; ZWICKER, 2000). Na fase de adaptação, o sistema é preparado para ser utilizado em uma determinada empresa, e é nela que se faz a eliminação de discrepâncias ou diferenças entre o pacote selecionado e a empresa (SOUZA; ZWICKER, 2000). Na parametrização, faz-se a adaptação do sistema ERP com o uso de valores de parâmetros disponibilizados pelo próprio sistema, com um mínimo de mudanças, o que evita custos de manutenção (SOUZA; ZWICKER, 2000). Na customização, o sistema ERP é modificado para adaptar-se a uma determinada situação empresarial impossível de ser reproduzida por parâmetros pré-existentes, sendo possível atender a qualquer necessidade da empresa (SOUZA; ZWICKER, 2000). Corrêa (1998) afirma que falhas no processo de implantação podem não só comprometer substancialmente as possibilidades de sucesso no uso de sistemas ERP (com as recorrentes consequências sobre a qualidade dos processos de tomada de decisão), como também sair extremamente caro à organização.

A implantação de um sistema ERP cumpre etapas sucessivas, nomeadas como ciclo de vida por Souza e Zwicker (2000), por incorporar a ideia de que sistemas passam por fases sucessivas de crescimento, evolução e declínio e de que, ao final deste ciclo, devem ser substituídos por outros sistemas para melhor atender às necessidades da empresa. Em sua forma tradicional, o ciclo de vida inclui as etapas de levantamento de requisitos do sistema, definição de escopo do projeto, análise de alternativas, projeto do sistema, codificação, testes, conversão de dados e 
manutenção. As fases de implantação mais comuns são: decisão e seleção, implementação e utilização (SOUZA; ZWICKER 2000; BRODBECK et al, 2010; OLIVEIRA; RAMOS JUNIOR; ALBUQUERQUE, 2010). Decisão e seleção constituem uma mesma etapa do processo de implantação dos sistemas ERP, porque a decisão de a empresa adotar ou não esse recurso ocorre concomitantemente com a seleção do fornecedor (SOUZA; ZWICKER, 2000). Antecede a essa etapa o entendimento de que o sistema ERP é uma ferramenta de apoio e de suporte, e não um fim em si mesmo, sendo o seu sucesso dependente da escolha do sistema mais adequado às necessidades da organização, da compreensão da dinâmica de seu funcionamento e da necessidade de alinhá -lo às estratégias empresariais e do desenvolvimento de uma cultura que assimile as mudanças introduzidas na organização, o que conduz ao rompimento com os costumes tradicionais.

Etapa inicial do processo, esta pressupõe a compreensão dos processos da organização e das suas oportunidades de mudança, uma vez que a escolha do software entre as opções disponíveis no mercado depende do negócio da empresa, e cada uma de suas necessidades implica a utilização de um módulo diferente, para o qual cada fornecedor oferece várias abordagens (OLIVEIRA; RAMOS JUNIOR; ALBUQUERQUE, 2010).

A implementação é a segunda etapa do ciclo de vida de sistemas ERP e pode ser definida como o processo pelo qual os módulos do sistema são colocados em funcionamento na organização, o que significa iniciar a utilização do sistema no processamento de transações empresariais (SOUZA; ZWICKER, 2000). Existe um consenso na literatura de que a implementação é a fase mais complexa da implantação do sistema ERP (OLIVEIRA; RAMOS JUNIOR; ALBUQUERQUE, 2010), que é compartilhado por Souza e Zwicker (2000), para quem a implementação é a fase mais crítica do processo de implantação. Essa fase contempla tarefas que vão desde o término do planejamento do processo de implementação até o momento do início da operação (SOUZA; ZWICKER, 2000).

$O$ processo de implementação é realizado em várias etapas de adaptação, uma para cada módulo ou grupo de módulos, que ocorrem simultânea ou sequencialmente, de acordo com o que foi definido no plano geral de implementação (SOUZA; ZWICKER, 2000, p.51). Entre os fatores que favorecem o sucesso da implementação do sistema ERP, destaca-se o envolvimento da alta direção, que se manifesta: pelo comando da etapa de planejamento, considerada a mais importante e também a mais negligenciada; pela conexão estratégica, com foco na execução pelos técnicos do que é melhor para a empresa e não do que esses profissionais pensam ser meIhor; pela formulação de objetivos estratégicos, na ação de traduzir para os usuários do sistema a visão da empresa e sua estratégia e de definir como o sistema ERP ajudará a empresa a cumprir suas prioridades (BUCKOUT; FREY; NEMEC JR., 1999). A etapa de implementação é finalizada com as atividades de treinamento dos usuários e a preparação do ambiente de operação contínua do sistema (SOUZA; ZWICKER, 2000).

O início da utilização do sistema exige que ele tenha sido adequadamente parametrizado, customizado (se necessário) e que: os dados iniciais tenham sido inseridos no sistema; os processos tenham sido alterados para adaptarem-se à utilização do sistema; o equipamento e software a serem utilizados para o processamento (servidores, sistemas operacionais, bancos de dados, redes, microcomputadores) tenham sido adequadamente instalados e configurados; os funcionários que irão interagir com o sistema estejam devidamente treinados, e as condições para obter suporte e auxílio tenham sido disponibilizadas de forma adequada (SOUZA; ZWICKER, 2000). A utilização é a etapa em que se descobrem todas as possibilidades do software. Esse processo ocorre depois que os usuários já tenham mais familiaridade com o sistema, sendo vital o comprometimento de todos eles (CORRÊA, 1998; OLIVEIRA; RAMOS JUNIOR; ALBUQUERQUE, 2010). 


\subsection{Mudança Organizacional Decorrente da Implantação do Sistema ERP}

A implantação de modelos gerenciais gera mudanças organizacionais e provoca expectativas em seus usuários e beneficiários. Além da mudança tecnológica, a implantação do sistema ERP, pela inovação inerente ao sistema, provoca mudança no comportamento da organização, por gerar incertezas e causar insegurança. No sentido de interferir nesse quadro, a direção da empresa tem por responsabilidade assegurar que o sistema provoque melhorias nos processos de trabalho e fluxos de informações, o que deve ser trabalhado junto às pessoas, de forma que todos tenham confiança, saibam entender e utilizar a tecnologia a seu favor, melhorando seu desempenho e produtividade (OLIVEIRA, 2006).

Gerenciar a mudança em um ambiente organizacional implica mudança de hábitos dos modelos de comportamento e das atitudes das pessoas em relação ao modo de execução, tanto em atividade de manufatura quanto em serviços (TAMAE et al., 2005). Na visão de Netto (2006, pág.), a grande dificuldade a ser superada pelos responsáveis pela administração das atividades de mudança nas organizações públicas é a noção, já incorporada, "de que são imortais e imutáveis" [...]. A estabilidade ocupacional leva os funcionários a uma tendência maior para a manutenção do status quo (CHAVES; MARQUES, 2006). Outro desafio é convencer os integrantes dessas instituições de que, ainda segundo Netto (2006), o momento é rico de oportunidades e de apelos à aplicação de esforços sistemáticos de transformação nas organizações públicas.

Robbins (2005) afirma que uma das descobertas mais bem documentadas nas pesquisas sobre comportamento organizacional é que as organizações e seus membros resistem à mudança. Essa resistência pode ser fonte de conflitos funcionais, o que dificultaria o processo de implantação da mudança. Essa resistência, ainda segundo Robbins (2005), pode ser aberta, implícita, imediata ou protelada. A resistência aberta e imediata é mais fácil de ser enfrentada, o maior desafio é administrar a mudança quando ela é implícita ou protelada.

Na visão de Schein (1980) apud Pereira (1995), o processo de mudança compõe-se de quatro fases: percepção, mudança de atitude, mudança de comportamento e fixação do novo comportamento. A percepção, o passo inicial do processo decisório e da aprendizagem, é o que traz motivação e vontade para mudar. A rotina, a padronização e a burocracia, entre outros, são escudos que tolhem novas percepções e engessam os sistemas, estando muito bem representadas nas estruturas organizacionais concebidas como imutáveis (PEREIRA, 1995). A mudança de atitude implica desaprender, descongelar padrões antigos, flexibilizar estruturas enrijecidas, desistir de algo que foi conquistado com esforço e que pode ter sido útil ou válido em outros tempos. Essa mudança somente efetiva-se quando ocorre internamente. A fixação do novo comportamento, habilidade identificada como "o aprender a aprender", é vital para as organizações porque realça sua capacidade de autorrenovação, o que significa perder o medo de mudar (PEREIRA, 1995).

Ao alterar substancialmente a posse da informação na organização, a implantação de sistemas ERP provoca, ainda, mudanças na forma de fazer negócios e no balanço de poder dentro da organização, além da resistência dos envolvidos no processo que, em alguns casos, intensifica-se quando implica o uso de sistemas informatizados (CORRÊA, 1998; CATELLINO; BOTTER; ITELVINO, 2010).

\section{METODOLOGIA}

A pesquisa realizada foi de natureza qualitativa (etapa 1) e quantitativa (etapa 2), do tipo descritiva, desenvolvida por meio de um estudo de caso. Usou-se, como unidade de análise, 
o Instituto Federal de Minas Gerais (IFMG) e, como sujeitos, os seus servidores, futuros usuários do sistema ERP, selecionados por amostragem, amostra não probabilística e por conveniência.

A pesquisa foi realizada em duas etapas: a primeira foi realizada por meio de entrevistas semiestruturadas direcionadas aos membros do Comitê Executivo do Projeto, por ser o fórum da tomada de decisões estratégicas e da coordenação das ações do Projeto de implantação do sistema ERP, denominado de "Conecta IFMG". Ao todo, foram realizadas dez entrevistas: 1) Patrocinador - Reitor do IFMG; 2) Gerente Executivo - Diretor de TI; 3) Gerente do projeto; 4) Analista Educacional - Servidor da Diretoria de TI; 5) Analista Administrativo - Servidor da Diretoria de TI; 6) Gestor de Processo 1 - Servidor da Diretoria de; 7) Gestor de Processo 2 - Pró-reitor de Planejamento; 8) Gestor de Processo 3 - Pró-reitor de Ensino; 9) Gestor de Processo 4 - Pró-reitor de Administração; 10) Pró-reitor de Extensão.

A análise de dados desta etapa se deu por análise de conteúdo, a partir das seguintes categorias de análise: 1) Planejamento da Implantação; 2) Impactos Previstos; 3) Desafios da Implantação.

Na segunda etapa da pesquisa, foi utilizada a Técnica de Configuração de Imagens Ideativas, por meio de um questionário de evocação livre (QEL), que foi enviado a 230servidores do Instituto, selecionados para, em um primeiro momento, integrarem a equipe de implantação do sistema ERP. Sessenta deles (26,1\%) responderam o instrumento de pesquisa.

A Técnica de Configuração de Imagens Ideativas integra o Método de Configuração de Imagem (MCl), fundamentado na Teoria das Representações Sociais inaugurada pelo francês Serge Moscovici, em 1961, com a publicação da obra La Psychanalyse, Son Image et Son Public, representando valiosa contribuição para a compreensão dos mais variados objetos e produção de conhecimento (PATRIOTA, 2007). A forma como o indivíduo vê e interpreta o mundo influencia o seu comportamento. Nesse sentido, os indivíduos não são apenas processadores de informações, mas pensadores ativos que "produzem e comunicam incessantemente suas próprias representações e soluções específicas para as questões que se colocam a si mesmos" (MOSCOVICl, 1984; apud PATRIOTA, 2007, p.2). As imagens constituem os conceitos e as relações que um indivíduo utiliza para compreender as várias situações ou os ambientes em que está inserido (MILAN; DE TONI, 2008).

Na visão de Milan e De Toni (2008), duas teorias merecem destaque na busca do entendimento de como as imagens organizam-se na memória de um indivíduo: a Teoria das Representações Sociais e a Teoria do Núcleo Central. A Teoria das Representações Sociais apresenta a formação dos modelos mentais como um processo socialmente mediado, em que o grupo de pessoas e seu comportamento, o contexto organizacional e os canais de informação são agentes influenciadores na formação das imagens dos indivíduos. Para Moscovici (2000; apud Milan e De Toni, 2008), as representações sociais são um conjunto de convicções, crenças e valores compartilhados pelas pessoas; têm como finalidade tornar familiares os eventos, assegurando a possibilidade de compartilhamento da rede de significados atribuídos a tais representações.

A Teoria do Núcleo Central sugere que o homem organiza e processa as informações de forma dinâmica e evolutiva, em torno de um núcleo central e de um conjunto de elementos periféricos. O núcleo central é determinado pela natureza do objeto representado e pela relação que o sujeito mantém com esse objeto, e os atributos que o compõem são marcados pela memória coletiva, cuja função é gerar significação para as imagens (MILAN; DE TONI, 2008). Em torno do núcleo central da imagem, há o sistema periférico, constituído pelos atributos mais flexíveis, sensíveis ao contexto imediato. Sua função é permitir a adaptação à realidade, bem como a diferenciação do conteúdo e a proteção ao sistema central. Os sistemas periféricos estão mais próximos das práticas do cotidiano e sujeitos às mudanças (MILAN; DE TONI, 2008). As imagens da 
primeira e segunda periferia indicam perspectivas gerais e constituem outra forma de entender os pensamentos e sentimentos das pessoas. As imagens da periferia relacionam-se a expressões do cotidiano, por estarem alocadas na 'superfície do pensamento', são facilmente acessadas (DE TONI; SCHULER, 2007).

Para verificar a receptividade ao projeto de implantação do sistema ERP no IFMG, através de imagens construídas pelos futuros usuários do sistema, utilizou-se o questionário de evocação livre (QEL), elaborado a partir de um roteiro básico de questões (QUADRO 1), cuja função é estimular a manifestação espontânea de ideias que compõem as imagens mentais dos respondentes, relativas à implantação da ferramenta de gestão integrada.

Milan e De Toni (2008) entendem que as questões 1 e 2 buscam verificar os atributos mais prontamente evocados da memória do pesquisado quando o objeto de pesquisa é citado, representando o tom geral da representação mental que o respondente tem sobre o conceito. As questões 3 a 6, por sua vez, buscam dar uma maior consistência à coleta de dados ao repetir o mesmo questionamento básico por meio de outras perspectivas (cognitiva, emocional e funcional), propondo ao respondente mais oportunidades de revelar os conceitos que fazem parte da configuração da sua imagem.

QUADRO 1 - Roteiro básico de questões

\begin{tabular}{|l|l|}
\hline \multicolumn{1}{|c|}{ Questões } & Tipo de evocação \\
\hline 1. Quando digo (termo indutor), qual é a primeira coisa que lhe vem à mente? & Top of mind \\
2. Que outras ideias lhe vêm à mente sobre (termo indutor)? & Geral \\
3. Como você descreve um (termo indutor)? & Cognitiva \\
4. Qual é o significado de (termo indutor) no IFMG (no seu campus?) & Simbólica \\
5. Quais os sentimentos que lhe vêm à mente quando digo (termo indutor)? & Emocional \\
6. Que benefícios o (termo indutor) traria para o IFMG? & Funcional \\
\hline
\end{tabular}
Fonte: Milan; De Toni (2008, p.112)

Após a aplicação do questionário de evocação livre, aplicou-se a análise por aproximações semânticas (BARDIN, 2011), criou-se uma tabela, contendo as ideias identificadas. Para cada uma delas, calculou-se o valor de frequência (VF), o valor de ordem (VO) e o valor total (VT). O primeiro valor indica o número de vezes que a ideia foi citada pelos respondentes; o segundo, a ordem em que foi citada; o terceiro, o somatório simples entre VF e VO. Para calcular o VO, adotou-se o procedimento proposto por Schuler (2000) (apud DE TONI (2005); MILAN; DE TONI (2008): a ideia citada em primeiro lugar recebeu o valor 5; a citada em segundo lugar, o valor 4; em terceiro lugar, o valor 3; em quarto lugar, o valor 2; e, em quinto lugar, o valor 1. A partir da sexta posição de evocação, as manifestações não receberam valor algum. $O$ cálculo da ordem de evocação das ideias permitiu identificar aquelas mais próximas e as mais distantes em relação ao termo indutor empregado (sistema ERP). As manifestações que se destacaram por uma alta frequência de citação (VF) e por um alto valor de ordem (VO), portanto, por um alto valor total (VT), compõem o núcleo central da imagem, e as demais, integram as periferias desse núcleo. Com a finalidade de enriquecer a análise do resultado deste estudo, fez-se, pelo critério de julgamento do pesquisador, a categorização das imagens identificadas pelos respondentes segundo os elementos cognitivos, funcionais, simbólicos e emocionais que caracterizam a imagem ideativa. Os resultados identificados com a aplicação da Técnica de Configuração de Imagens Ideativas foram representados através do gráfico de configuração das imagens. 


\section{DESCRIÇÃO DO CASO ESTUDADO: O PROJETO "CONECTA IFMG"}

O IFMG, uma autarquia integrante da Rede Federal de Educação Profissional, Científica e Tecnológica, vinculada ao Ministério da Educação, criada por força da Lei n. 11.892, de 29 de dezembro de 2008, é uma instituição de educação superior, básica e profissional, pluricurricular e multicampi, especializada na oferta de educação profissional e tecnológica nas diferentes modalidades de ensino, com base na conjugação de conhecimentos técnicos e tecnológicos com as suas práticas pedagógicas (BRASIL, 2008). É uma organização resultante da fusão do CEFET de Ouro Preto e sua unidade descentralizada de Congonhas; do CEFET de Bambuí e sua unidade descentralizada de Formiga; e da Escola Agrotécnica Federal de São João Evangelista, transformados em seus respectivos campi.

O IFMG constitui-se de dez campi, um núcleo avançado e quatro unidades conveniadas, o que faz a sua abrangência territorial alcançar, além da Região Metropolitana de Belo Horizonte, as regiões dos Campos das Vertentes, Central Mineira, Sul e Sudoeste de Minas, Oeste de Minas, Zona da Mata e Vale do Rio Doce. Conta, em seu quadro de pessoal, com 1.500 (hum mil e quinhentos) funcionários e tem aproximadamente 14.000 alunos matriculados em seus 51 cursos, distribuídos pelas modalidades de formação inicial e continuada, ensino técnico (integrado ao ensino médio, concomitante, subsequente e educação de jovens e adultos), ensino superior (bacharelado, licenciatura e tecnologia) e pós-graduação lato sensu. A constatação da ausência, em seus diversos campi, de um sistema de informação adequado a uma gestão acadêmica e administrativa eficaz e a verificação da inexistência de solução de software livre, no portal do software público e na comunidade livre que atendesse às necessidades da Instituição levaram os gestores do IFMG a optarem pela implantação do sistema integrado de gestão na modalidade ERP (Enterprise Resources Planning).

A opção pela aquisição do sistema ERP levou em conta a dificuldade para o desenvolvimento interno de um sistema de informação adequado à realidade e às necessidades do Instituto; as qualidades do sistema, representadas por sua eficiência, eficácia e efetividade; a robustez da ferramenta; o tempo de seu uso pela iniciativa privada, estando, portanto, a sua aplicação validada por organizações de grande e médio porte no mundo e no Brasil e, ainda, a aprovação de sua aquisição pelo Colégio de Dirigentes e pelo Comitê de TI do IFMG.

\section{OS RESULTADOS DA PESQUISA}

\subsection{Parte 1: Planejamento, Impactos e Desafios da Implantação do Sistema ERP}

Planejamento da Implantação: No projeto de implantação, a compra do sistema ERP destaca-se como uma fase a que se dedicaram cuidados especiais. Por se tratar de uma compra pública, fundamentada na legislação pertinente, deu-se por processo licitatório, através de pregão eletrônico, com as exigências do Instituto explicitadas em edital elaborado para a finalidade indicada. A construção desse instrumento de compra pública obedeceu a uma programação iniciada em dezembro de 2009, com os contatos com fornecedores especializados para conhecimento dos sistemas de gestão disponíveis. Depois de aproximadamente oito meses, concluiu-se a fase de compra do sistema ERP, com a contratação da empresa vencedora do processo licitatório, a TOTVS S.A.

Pesquisas realizadas com a iniciativa privada evidenciam que os custos de implantação de um sistema ERP são muito altos, o que constitui um risco para a concretização do processo. 
Com foco na redução desses custos, o Instituto fez opção pelo conceito roll-out de implantação, que consiste em definir uma metodologia de implantação para um campus indicado pelo IFMG juntamente com a Reitoria. Optou-se também pela estratégia da implantação compartilhada, que se subdivide em: implantação acompanhada (a TOTVS executa, e a equipe de TI do IFMG acompanha os trabalhos); implantação assistida (o IFMG executa, e a TOTVS assiste a execução) e implantação autônoma (todo o trabalho é realizado pelo IFMG com o suporte da TOTVS).

Quando se compara os custos de implantação do sistema ERP no IFMG $(\mathrm{R} \$ 2.395 .000,00)$ com os custos da iniciativa privada (em média, entre 5 a 8 milhões), verifica-se uma diferença significativa entre eles. Dois fatores parecem justificar essa diferença. Um deles é que, na iniciativa privada, contabilizam-se todos os custos, os financeiros e os econômicos, o que não se deu no Instituto, onde o custo da implantação refere-se somente ao projeto de implantação. O outro fator relaciona-se com o fato de ser o IFMG a primeira instituição pública federal de ensino técnico a implantar o sistema ERP, estando esse nicho de mercado, o dos institutos federais de ensino, aberto à implantação dessa ferramenta de gestão. Acredita-se que o sucesso da TOTYS na implantação do sistema no Instituto a qualifique para a conquista desse mercado, o que justifica o preço que a fez vencedora do processo licitatório:

[...] Nós fomos a primeira escola técnica do Brasil a comprar o ERP. Estamos enfrentando, aí, resistências políticas internas e externas, temos críticas positivas e negativas... [...] na hora que a gente procurou a iniciativa privada, eles viram o tamanho do mercado em que eles não atuam, que é totalmente virgem esse mercado. (GESTOR DE PROCESSO 3).

A implantação do sistema ERP no Instituto dar-se-á em duas grandes etapas que se complementam: a implantação geral e a implantação por unidade. A implantação geral constituise das ações de preparação dos processos da Instituição a serem parametrizados pela TOTVS, e a implantação por unidade, das ações voltadas para a implantação dos sistemas parametrizados nos campi e na Reitoria, conforme cronograma estabelecido.

A composição das equipes de implantação, referentes aos módulos relacionados e ao suporte, contou com a participação dos pró-reitores e dos diretores-gerais dos campi respectivamente, levando-se em conta a representatividade, a competência técnica dos servidores, a sua capacidade de envolvimento e a sua afinidade com o projeto político-pedagógico dos campi e da Reitoria. A metodologia de implantação do sistema ERP no IFMG foi a Metodologia de Implantação TOTVS (MIT), que: 1) baseia-se nas nove Áreas de Conhecimento em Gerenciamento de Projetos do PMBOK do PMI; 2) é flexível ao perfil do cliente e ao tipo de projeto; 3 ) reduz a subjetividade em benefício da objetividade, permitindo a percepção e o acompanhamento da evolução do progresso do projeto, e 4) possibilita maior eficiência e transparência nos controles.

Impactos da Implantação: Na visão dos pesquisados, a implantação do sistema ERP no Instituto é um reforço ao modelo participativo de gestão, significando a construção desse modelo e, consequentemente, a construção da identidade do Instituto. O impacto da implantação é mais expressivo sobre os processos do Instituto, uma vez que todos eles serão estudados em profundidade, reavaliados, recuperados, definidos e padronizados, antes de serem parametrizados pela TOTVS. Dessa forma, far-se-á a construção do processo organizacional.

Entende-se que, em relação às pessoas, a implantação do sistema ERP é uma oportunidade ímpar para combater o isolamento e o personalismo, valorizar o conhecimento adquirido pelos servidores experientes, promover o trabalho em equipe e a socialização do conhecimento e estimular a mudança de mentalidade e de visão. 
[...] o sistema é fantástico, mas muito mais importante que o sistema são as pessoas; o sistema nada mais é que uma ferramenta de trabalho. Então, as pessoas precisam acreditar nesse sistema, e isso implica, em alguns casos, mudança de comportamento. Não vai dar para a pessoa fazer aquilo que ela fez a vida inteira, ela vai precisar mudar a sua forma de trabalhar (GESTOR DE PROCESSO 2).

Desafios da Implantação: O fato de ser o Instituto a primeira instituição pública federal de ensino técnico a implantar o sistema ERP amplia esse desafio e exige das equipes responsáveis pela implantação do projeto uma disposição permanente para a superação desse desafio, que se manifesta, não só pelas dificuldades, mas principalmente pelas mudanças que acontecem com a implantação. A pesquisa identificou uma série de dificuldades que poderão tornar o processo de implantação mais trabalhoso e mais desgastante. Dentre elas, os entrevistados destacam: 1) A não ampliação do quadro de servidores da equipe de TI do Instituto, responsáveis pela implantação; 2) Sobrecarga de trabalho, implicando acúmulo de atividades para efetivar a implantação do sistema; 3) Desconhecimento dos benefícios da ferramenta para o dia a dia do trabalho; 4) Não cumprimento de prazos em função do desconhecimento de interfaces existentes entre elementos de um determinado processo e de outras ocorrências; 5) Monopólio dos líderes na condução do processo de implantação do sistema ERP; 6) Uso do projeto de implantação como ferramenta de projeção política; 7) Resistência diante da mudança, do novo.

[...] num determinado, local nós vamos ter uma rede de extração de dados ruim; num campus mais antigo, você vai ter que substituir e não tem dinheiro para aquilo [...] mas são coisas pontuais, que se resolvem com uma certa facilidade, sabe? Sem um estresse muito grande. A maior dificuldade, para mim, é a disponibilidade das pessoas, porque, durante algum período, elas vão ter que se desdobrar mesmo, fazer o que elas já faziam mais alguma coisa (GESTOR DE PROCESSO 1).

As ações para superação dessas dificuldades valorizam o incentivo à participação e ao exercício da comunicação, o que justifica a presença de um analista de marketing na equipe de implantação do sistema. As principais ações de superação foram destacadas pelos entrevistados: 1) Intenção de disponibilizar toda capacidade do Instituto para superação das dificuldades da implantação; 2) Acompanhamento da implantação, incentivando a mobilização da comunidade, o envolvimento com o projeto e o trabalho em equipe; 3) Democratização das decisões relativas à implantação do sistema ERP; 4) Exercício permanente do convencimento; 5) Investimento em treinamento e capacitação; 6) Realização de reuniões de conscientização, os workshops de formação de líderes.

Há uma unanimidade entre os entrevistados em apontar a profissionalização da gestão, fundamentada em informações compartilhadas, unidas numa mesma base de dados, obtidas em tempo real, como um dos principais resultados esperados da implantação do sistema ERP na Instituição. Esperam-se ainda, dentre outros: a consolidação do trabalho participativo e do trabalho em equipe, evidenciando a integração entre os servidores; a consolidação do princípio da unicidade do Instituto, manifestada na padronização de seus processos registrados no manual de gestão.

\subsection{Parte 2: Configuração das Imagens Ideativas sobre o Projeto "Conecta IFMG"}

O levantamento das ideias dos respondentes relativas ao termo indutor, Sistema ERP, conduziu à identificação de 41 (quarenta e uma) manifestações que formam a imagem dos pesquisados sobre a ferramenta de gestão indicada. A TAB.1 relaciona essas manifestações com seus correspondentes valores de frequência (VF), valores de ordem (VO) e valores totais (VT), e a sua distribuição pelas dimensões que caracterizam a configuração da imagem. 
TABELA 1 - Imagens identificadas pelas dimensões da configuração da imagem

\begin{tabular}{|c|c|c|c|c|c|}
\hline Imagens & $\mathbf{N}$ & Manifestações & VF & Vo & VT \\
\hline \multirow{4}{*}{$\begin{array}{l}\text { Imagem } \\
\text { central }\end{array}$} & 1 & Integração & 60 & 273 & 333 \\
\hline & 2 & Gestão profissional & 41 & 204 & 245 \\
\hline & 3 & Software de gestão, modelo gerencial & 35 & 182 & 217 \\
\hline & 4 & Processos, definição e padronização & 36 & 153 & 189 \\
\hline \multirow{5}{*}{$\begin{array}{l}\text { Primeira } \\
\text { periferia }\end{array}$} & 5 & Melhorias: de processos, do trabalho, do controle & 33 & 142 & 175 \\
\hline & 6 & Agilidade & 31 & 138 & 169 \\
\hline & 7 & Tecnologia, avanço, inovação, modernidade & 30 & 137 & 167 \\
\hline & 8 & Diagnóstico, planejamento, organização & 28 & 131 & 159 \\
\hline & 9 & Informação em tempo real, confiáveis, unificadas & 27 & 115 & 142 \\
\hline \multirow{16}{*}{$\begin{array}{l}\text { Segunda } \\
\text { periferia }\end{array}$} & 10 & Eficiência, eficácia e efetividade & 24 & 93 & 117 \\
\hline & 11 & Controle & 18 & 84 & 102 \\
\hline & 12 & Facilidade no trabalho e na comunicação & 16 & 71 & 87 \\
\hline & 13 & Economia de esforços, de recurso, de tempo & 12 & 49 & 61 \\
\hline & 14 & Segurança na tomada de decisão & 13 & 47 & 60 \\
\hline & 15 & Apreensão, medo, insegurança, ansiedade, resistência & 11 & 45 & 56 \\
\hline & 16 & Esperança de melhoria & 9 & 45 & 54 \\
\hline & 17 & Sistema de informação, fluxo de informação & 9 & 44 & 53 \\
\hline & 18 & Praticidade, produtividade, fortalecimento operacional & 10 & 40 & 50 \\
\hline & 19 & Banco de dados único & 8 & 39 & 47 \\
\hline & 20 & Comodidade, conforto, alívio, tranquilidade & 8 & 38 & 46 \\
\hline & 21 & Transparência & 9 & 35 & 44 \\
\hline & 22 & Envolvimento, comprometimento, desapego, dinamismo & 8 & 31 & 39 \\
\hline & 23 & Mudança & 7 & 30 & 37 \\
\hline & 24 & Expectativa & 6 & 29 & 35 \\
\hline & 25 & Redução duplicidade de informação; eliminação do retrabalho & 7 & 27 & 34 \\
\hline \multirow{16}{*}{ Periferia } & 26 & Gestão compartilhada, responsabilidade conjunta & 6 & 27 & 33 \\
\hline & 27 & Qualidade do trabalho, qualidade de vida & 7 & 25 & 32 \\
\hline & 28 & Projeto IFMG & 5 & 24 & 29 \\
\hline & 29 & Unicidade do Instituto & 5 & 24 & 29 \\
\hline & 30 & Satisfação, felicidade, contentamento & 4 & 18 & 22 \\
\hline & 31 & Motivação, otimismo & 4 & 17 & 21 \\
\hline & 32 & Profissionalização & 4 & 16 & 20 \\
\hline & 33 & Dificuldade, confusão, dúvidas, incompreensão & 7 & 32 & 18 \\
\hline & 34 & Conhecimento & 3 & 11 & 14 \\
\hline & 35 & Burocracia & 2 & 10 & 12 \\
\hline & 36 & Desafio & 2 & 8 & 10 \\
\hline & 37 & Engrandecimento, valorização & 2 & 7 & 9 \\
\hline & 38 & Fiç̧ão científica & 1 & 5 & 6 \\
\hline & 39 & Lembranças & 1 & 5 & 6 \\
\hline & 40 & Mundo empresarial & 1 & 5 & 6 \\
\hline & 41 & Uma bênção & 1 & 5 & 6 \\
\hline TOTAL & & & 551 & & \\
\hline
\end{tabular}

Fonte: Dados da pesquisa, 2011 
A distribuição das manifestações relacionadas em torno do termo indutor, orientada pelo cálculo dos quartis, permite verificar que $9,75 \%$ das manifestações compõem a imagem central e a primeira periferia; $17,00 \%$, a segunda periferia; e $63,40 \%$, a periferia (TAB.2)

As distribuições percentuais de menor valor $(9,75 \%)$ concentram as manifestações com maiores VT, representando as ideias que, por sua ordem de manifestação pelos respondentes, receberam uma pontuação maior, significando, possivelmente, as imagens de maior significado para eles. A distribuição percentual de maior valor $(63,40 \%)$ representa as manifestações com menores VT, representando as manifestações de menor pontuação e, provavelmente, as mensagens de menor significação para os respondentes.

TABELA 2 - Áreas de proximidade das manifestações em relação ao termo indutor

\begin{tabular}{c|c|c|c}
\hline Quartis & Áreas de proximidade & Intervalos do VT & Distribuição percentual \\
\hline $\mathbf{4}$ & Imagem central & De 189 a 333 & $4(9,75 \%)$ \\
$\mathbf{3}$ & Primeira Periferia & De 159 a 175 & $4(9,75 \%)$ \\
$\mathbf{2}$ & Segunda Periferia & De 56 a 142 & $7(17,0 \%)$ \\
$\mathbf{1}$ & Periferia & De 6 a 54 & $26(63,4 \%)$ \\
\hline
\end{tabular}

Fonte: Dados da pesquisa, 2011

Das manifestações que formam a imagem dos respondentes sobre o sistema ERP, $43,02 \%$ pertencem à categoria dos elementos funcionais: nessa categoria, as imagens correspondentes a software de gestão, modelo gerencial e melhorias diversas (do trabalho, do controle e de processos) são as mais compartilhadas; $38,21 \%$ das manifestações compõem a categoria dos elementos cognitivos, com destaque para a socialização das imagens integração e gestão profissional; os elementos emocionais representam $12,37 \%$ das manifestações: nesse grupo, segurança na tomada de decisões de um lado e apreensão, medo, insegurança, ansiedade e resistência de outro, são as manifestações que se projetam por serem as mais socializadas; na categoria dos elementos simbólicos, têm-se 6,38\% das manifestações, sendo as imagens da praticidade, produtividade, fortalecimento operacional e da transparência as mais compartilhadas.

O gráfico de configuração da imagem (CGI), FIG.1, resultante da aplicação da Técnica de Configuração de Imagens Ideativas, e da Tabela 1 demonstram as principais ideias que os futuros usuários-chave do sistema ERP no IFMG têm sobre essa ferramenta de gestão. O GCl evidencia três informações significativas além de formar uma rede de significados socialmente aceitos e compartiIhados: as manifestações que compõem as imagens relativas ao sistema ERP; a proximidade dessas manifestações com o termo indutor empregado (sistema ERP); e as categorias representativas dos elementos funcionais, simbólicos, cognitivos e emocionais que caracterizam a imagem ideativa.

O GCl, para a amostra pesquisada, configura como imagem central as manifestações correspondentes à integração, à gestão profissional, ao software de gestão e modelo gerencial, e a processos, definição e padronização. Essas manifestações além de representarem, conforme asseveram Milan; De Toni (2008), elementos mais estáveis e mais resistentes à mudança, são responsáveis pela sustentação da imagem compartilhada pelos respondentes, sendo prontamente lembradas. Nessa linha de raciocínio, as manifestações localizadas nas periferias representam imagens mais flexíveis, mais próximas do cotidiano, e sensíveis ao contexto imediato, não sendo amplamente compartilhadas nem prontamente lembradas. 


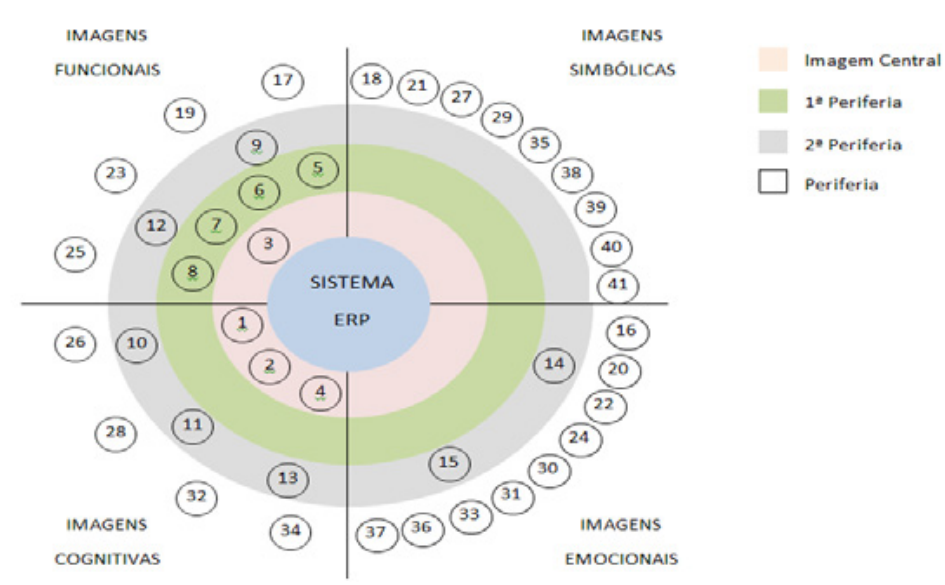

Figura 1: Gráfico da Configuração das Imagens (GCl)

Fonte: Dados da Pesquisa, 2011

Em relação à distribuição das manifestações pelos elementos que caracterizam a imagem ideativa, observa-se que três das quatro imagens que configuram a imagem central pertencem à categoria dos elementos cognitivos, representando construções mentais evocadas pelos respondentes sobre sistema ERP. Observa-se, ainda, que todas as manifestações que compõem os elementos simbólicos localizam-se na periferia da imagem, não sendo, portanto, imagens compartilhadas.

Embora haja um equilíbrio numérico entre as manifestações distribuídas pelas categorias citadas, percebe-se, na sua distribuição pelas respectivas áreas do $\mathrm{GCl}$, uma concentração nas categorias dos elementos funcionais e cognitivos, com destaque para os elementos funcionais. Essa distribuição pode ser vista como um fator favorável ao sucesso da implantação do sistema ERP, com foco na praticidade da ferramenta, e no entendimento de seu significado como software de gestão.

A comparação do conteúdo do $\mathrm{GCl}$ (FIG.1) e da TAB. 1 com a expectativa dos usuários evidencia uma estreita relação entre as imagens dos servidores, os usuários-chave do sistema, e as expectativas dos gestores de ponta da Instituição, membros do comitê executivo, sobre a implantação do sistema ERP no Instituto.Quando não se repetem, as informações se complementam, mostrando que há, no Instituto, uma expectativa positiva sobre a implantação do sistema ERP.

\section{CONSIDERAÇÕES FINAIS}

O objetivo deste estudo foi o de descrever as ações de planejamento para a implantação de um sistema integrado de gestão na modalidade ERP, em uma instituição pública federal de ensino técnico, capazes de minimizar os riscos inerentes à sua implantação. Nesse sentido, buscaram-se: a identificação das exigências, limitações, expectativas e benefícios da implantação do sistema ERP, no IFMG; a caracterização da metodologia de implantação utilizada pelo Instituto; a verificação das imagens construídas pelos futuros usuários do sistema ERP em torno do conceito, relacionando essas imagens com a receptividade da implantação.

Sendo o Instituto a primeira instituição pública federal de ensino técnico a implantar o sistema ERP, não se têm parâmetros para comparar e avaliar a qualidade do processo de implantação, mas indicadores evidenciados pela pesquisa apontam para um processo a se concretizar com custos e tempo menores aos praticados na iniciativa privada.

Riscos significativos de implantação não foram identificados pela pesquisa realizada. Aparentemente, as dificuldades apontadas não comprometem a implantação do sistema ERP no Instituto. Possíveis questionamentos do TCU, por estar-se implantando um sistema considerado 
'não oficial', são facilmente defensáveis pela evidência da prática dos princípios da eficiência, eficácia, efetividade e da economicidade que regem a administração pública.

A aplicação da Técnica de Configuração de Imagens permitiu identificar as imagens dos servidores do Instituto, futuros usuários do sistema ERP, sobre essa ferramenta de gestão. Essas imagens revelam conhecimentos, opiniões, expectativas, percepções e emoções sobre a implantação desse software no Instituto, imagens socializáveis e não socializáveis. Entende-se que as imagens positivas apresentam-se como um fator de sucesso da implantação, por favorecerem a receptividade das ações programadas; enquanto as negativas sugerem resistência ao processo, devendo ser substituídas a partir de ações adequadas a essa finalidade.

Coerente com De Toni; Schuler (2007), a posição dessas imagens nas diferentes áreas do $\mathrm{GCl}$ informa sobre a natureza da sua ligação com o conceito em estudo. Manifestações positivas, representativas da imagem central, reforçam a possibilidade de aceitação da implantação do sistema ERP no IFMG. Manifestações positivas nas periferias da imagem central indicam a possibilidade de aproximação dessas ideias da imagem central, trazendo uma melhoria geral na imagem do conceito estudado, ampliando a aceitação da implantação. Uma imagem negativa, no campo da imagem central, é evidência de dificuldades, que demanda tempo e investimento para ser superada, uma vez que sua ligação com o conceito estudado é forte. Já uma imagem negativa em área periférica indica a facilidade para a sua substituição por outra positiva a partir do desenvolvimento de ações pertinentes.

Espera-se que esta pesquisa possa constituir o ponto de partida para outros estudos relativos à implantação do sistema ERP em instituições públicas, já que o assunto não se esgotou com este trabalho. Espera-se também contribuir para o enriquecimento de estudos relativos à implantação, em instituições públicas, de sistemas integrados de gestão fundamentados em tecnologia da informação. 


\section{REFERÊNCIAS}

BRASIL. Lei n. 11.892, de 29 de dezembro de 2008. Institui a Rede Federal de Educação Profissional, Científica e Tecnológica, cria os Institutos Federais de Educação, Ciência e Tecnologia, e dá outras providências. Diário Oficial da União, 30 dez. 2008.

BARDIN, Lawrence. Análise de Conteúdo. Tradução de Luís Antero Reto e Augusto Pinheiro. São Paulo: Edições 70, 2011.

BRODBECK, Henrique J. et al. Configuração de um Processo de Seleção, Aquisição e Implementação de ERP Considerando os Grupos Sociais Envolvidos. Revista Eletrônica de Sistemas de Informação, v. 9, n. 01, 2010. Disponível em <<www.facecla.com.br/ revistas/resi>>. Acesso em 05-01-11.

BUCKOUT, S.; FREY, E.; NEMEC JR. Por um ERP Eficaz. HSM Management. set./out. 1999. Disponível em <<http://www.strategia.com. br/Arquivos >. Acesso em 06-01-2011.

CANUTO, Kleber Cuissi; MUSSI, Fabricio Baron; CHEROBIM, Ana Paula Mussi Szabo. Tomada de Decisões Isomórficas Para a Implantação de ERPs: um estudo de múltiplos casos. Revista Eletrônica de Sistemas de Informação, v. 9, n. 1, 2010. Disponível em <<www.facecla.com. $\mathrm{br} /$ revistas/resi > . Acesso em 05-01-11.

CATELLINO, Giovanni Gerson; BOTTER, Rui Carlos; ITELVINO, Lucimar da Silva. Os Fatores Críticos de Sucesso para a implantação de sistemas integrados de gestão no setor público. Anais. Simpósio de Excelência em Gestão e Tecnologia, 2010. Disponível em $<<h t t p: / /$ www.aedb.br/seget/artigos $>$. Acesso em 0601-11.

CHAVES, Rosana Costa e MARQUES, Antônio Luiz. Mudança Organizacional no Setor público: um estudo sobre o impacto das mudanças instituídas pelo Governo do estado de Minas Gerais numa instituição pública estadual. In: ENCONTRO NACIONAL DOS PROGRAMAS
DE PÓS-GRADUAÇÃO EM ADMINISTRAÇÃO - ENANPAD, 30, 2006, Anais. Salvador/ BA Disponível em 《 www.anpad.org.br/ enanpad/2006 > . Acesso em 10-01-11.

CORRÊA, Henrique Luiz. ERPs: Por que as implantações são tão caras e raramente dão certo? Simpósio de Administração da Produção, Logística e Operações Industriais, 1. Anais...1998. Disponível em <<http://www. correa.com.br/biblioteca/artigos $>$. Acesso em 20-01-11.

COSTA, Flávio Augusto Lima da. Governança eletrônica contra a fraude. Revista Custos Brasil Soluções Para o Desenvolvimento, set./out. 2009. Disponível em <<www. revistacustobrasil.com.br $>$. Acesso em 12-102010.

DE TONI, Deonir. Administração da Imagem de Produtos: Desenvolvendo um Instrumento Para a Configuração da Imagem de Produto. 2005. 268 f. Tese (Doutorado em Administração da Universidade Federal do Rio Grande do Sul) - Universidade Federal do Rio Grande do Sul, Porto Alegre, 2006. Disponível em <<www. scielo.br >>. Acesso em 29/08/2010.

DE TONI, Deonir; SCHULER, Maria. Gestão da imagem: desenvolvendo um instrumento para a configuração da imagem de produto. Revista de Administração Contemporânea, v. 1, n. 4, 2007. Disponível em $\ll$ www.scielo.br/scielo >>. Acesso em 18/01/2012.

ERKENS, Rainer (Org). Nova Gestão Pública e Democracia no Brasil. In: Nova Gestão Pública. São Paulo: Instituto Friedrich Nauname, abril, 2010, 46p. Disponível em <<http://ffn- brasil. org.br $>$. Acesso em 10-01-11

GAMA, Fernanda de Assis; MARTINELLO, Magnos. Governança de Tecnologia da Informação: Um Estudo em Empresas Brasileiras. In: SIMPÓSIO FUCAPE DE PRODUÇÃO CIENTÍFICA, 4, 2006, Vitória. Anais. FUCAPE Busines Schol... Vitória. Disponível em $<<$ www.fucape.br/simposio/4/artigos $>$. 
Acesso em 07-01-11.

HADAD, F. MINISTRO da Educação reconduz reitor do IFMG ao cargo. set. 2011. Disponível em $<<w w w . i f m g . e d u . b r>>$. Acesso em 20-092011.

MEDEIROS JR; Alberto de; PEREZ ,Gilberto; SHIMIZU, Tamio. Classificação de critérios para seleção de ERP: um estudo utilizando a técnica Delphi. Revista Eletrônica de Sistemas de Informação, v. 9, n. 1, 2010. Disponível em $<<$ www.facecla.com.br/revistas/resi >>. Acesso em 05-01-11.

MENDES, Juliana Veiga; ESCRIVÃO FILHO, Edmundo. Sistemas Integrados de Gestão ERP em Pequenas Empresas: um confronto entre o referencial teórico e a prática empresarial. Revista Gestão \& Produção, v.9, no3, p.227-

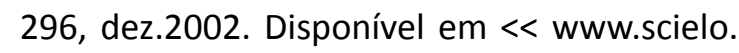
$\mathrm{br} \gg$. Acesso em 06-01-11.

MILAN, Gabriel Sperandio; DE TONI, Deonir. A Configuração das Imagens dos Gestores Sobre o Conceito de Estratégia. RAM - Revista de Administração Mackenzie, v. 9, no6, p.102125, set/out 2008. Disponível em $<<w w w 3$. mackenzie.br $>$. Acesso em 29-08-2010.

NETTO, Francisco Sobreira; GOUVÊA, Maria Aparecida; NETTO, João Eduardo. Avaliação de Desempenho de BPM na Administração Pública Brasileira com o Uso de Análise Multivariada. In: XXX ENANPAD, Salvador, 2006. Anais... Salvador: 2006. Disponível em <<www.anpad. org.br/evento.php >>. Acesso em 08/10/2010.

OLIVEIRA, Bruno Trevizan de; RAMOS JUNIOR, Moacir Pereira e ALBUQUERQUE, João Porto de. Implantação de um Sistema Integrado de Gestão no Modelo Software AS a Service (SAAS): um estudo de caso em uma pequena empresa de Engenharia. Revista Eletrônica de Sistemas de Informação, v. 9, n. 1, 2010. Disponível em <<www.facecla.com.br/ revistas/resi > . Acesso em 05-01-11.

OLIVEIRA, Lindomar Subtil de. Um Estudo
Sobre os Principais Fatores na Implantação de Sistemas ERP. 2006. 154 F. Dissertação (Mestrado em Engenharia da Produção) Universidade Tecnológica do Paraná, Campus Ponta Grossa, Ponta Grossa, 2006.

OLIVEIRA, Luciano. Evolução da Administração Pública no Brasil. 2007. Disponível em <http:// www.editoraferreira.com.br>. Acesso em 1101-11.

PATRIOTA, Lucia Maria. Teoria das Representações Sociais: Contribuições para a apreensão da realidade. Serviço Social em Revista v.10, n.1 - jul/dez/2007. Disponível em <http://www.ssrevista.uel.br>. Acesso em 29/08/2010.

PEREIRA, Luiz Carlos Bresser. A Reforma Gerencial do Estado de 1995. Revista de Administração Pública, v.34, n.4, jul. 2000: 55-

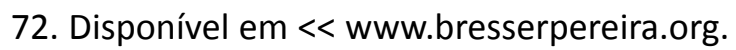
br $\gg$. Acesso em 10-01-11.

PEREIRA, M.J.B. Modelos de mudança em organizações brasileiras: uma análise crítica. In: BJUR e CARAVANTES. Reengenharia ou readministração? Porto Alegre: AGE, 1995.

ROBBINS, Stephen P. Mudança organizacional e administração do estresse. In.

Comportamento Organizacional. Tradução de Reynaldo Cavalheiro Marcondes. 11.ed. São Paulo: Pearson Prentice Hall, 2005. Cap18, p.421-457.

RODRIGUES, Rodrigo. AlnteligênciaCompetitiva Organizacional e os Sistemas Integrados de Gestão ERP: estudo nas indústrias calçadistas de Jaú. 2009. 127 f. Dissertação (Mestrado em Ciência da Informação - FFC) - Universidade Estadual Paulista, Marília, 2009. Disponível em < http://www.marilia.unesp.br/Home/PosGraduacão >>. Acesso em 06-01-11

SACCOL, A; MACADAR, M. A.; PEDRON, C. D.; LIBERALI NETO, G.; CAZELLA, S. C. Sistemas ERP e seu impacto sobre variáveis estratégicas de grandes empresas no Brasil. In: SOUZA, C; 
SACCOL, A. Sistemas ERP no Brasil - teoria e casos. São Paulo: Atlas, 2003.

SACCOL, Amarolinda Zanella; SOUZA, Cesar Alexandre de. Edição temática: ERP. Revista Eletrônica de Sistemas de Informação, v. 9, n. 1, 2010. Disponível em <<www.facecla.com. $\mathrm{br} /$ revistas/resi > . Acesso em 05-01-11.

SOUZA, C.; ZWICKER, R. Sistemas ERP: estudo de múltiplos casos em empresas brasileiras. In: SOUZA, C.; SACCOL, A. Sistemas ERP no Brasil. São Paulo: Atlas, 2003.

TAMAE, Rodrigo Yoshio; LEITE, Maria Carolina; FERREIRA, Tatiane Guerino Pereira; GOMES, Vivian Maria Barboza. Importância de Sistemas ERP nas Empresas de Médio e Pequeno Porte. Revista Científica Eletrônica de Sistemas de Informação, ano 2, n. 03, ag. 2005. Disponível em <<http://www.revista.inf.br >>. Acesso em 06-01-2011.

TAMEZ, Carlos André. Formas históricas de Administração Pública. 2004. Disponível em < http://www.cursoaprovacao.com.br/cms/ artigo.php $>>$. Acesso em 11-01-11.

VILHENA, Renata. O Choque de Gestão em Minas Gerais: Políticas de Gestão Pública Para o Desenvolvimento, 2006. Disponível em $<$ http://www.institutopublix.org.br/>. Acesso 05-01-11.

WOOD JR, Thomaz; CALDAS, Miguel P. Modismos em Gestão: Pesquisa Sobre a Adoção e Implementação de ERP. In: ENCONTRO NACIONAL DOS PROGRAMAS DE PÓS GRADUAÇÃO EM ADMINISTRAÇÃO - ENANPAD, 23, Anais, 1999. Disponível em <<http://www.ancibe.com.br/artigos >>. Acesso em 20-01-11. 
